\title{
An Approach towards Eco-labeling of Compressed Air Filters Based on Carbon Footprint
}

\author{
Wolfgang Mölter-Siemens ${ }^{1}$, Sebastian Kasselmann ${ }^{2}$, Sebastian Berlin ${ }^{2}$ and Christof Asbach ${ }^{1}$ \\ 1. E.V. Department, Institute for Energy and Environmental Technology (IUTA), Duisburg D-47229, Germany \\ 2. International Performance Research Institute (IPRI), Stuttgart D-70173, Germany
}

\begin{abstract}
Compressed air-a major industrial energy carrier, its filters are used to reach the required cleanliness level of compressed air. These filters, however, introduce a pressure drop which results in a loss of energy. It is shown that over the life cycle of a compressed air filter, the pressure drop dominates the total energy consumption and subsequently, the carbon footprint. From an economic as well as ecologic point of view, a reduction of the pressure drop is hence of utmost importance. Based on this finding and structuring, the wide range of applications and operational parameters, a pragmatic and technically feasible eco-labeling system for compressed air filters was developed as a decision supporting tool. Using this tool, procurement managers as well as the process engineers and environmental officers are able to steer the selection of suitable compressed air filters. The approach has been proposed to and discussed with various representatives of the compressed air filter industry nevertheless there is probably a long way to go to establish such a labeling procedure in industry.
\end{abstract}

Key words: Eco-labeling, carbon foot print, life cycle assessment, compressed air filters and product category rules.

\section{Introduction}

Compressed air is one of the most important energy carriers for industrial processes and applications, e.g. electronics, life sciences, health care and chemical processing systems. In European Union, approximately 320,000 compressors are installed in industry with an estimated annual energy input of approximate 80 billion $\mathrm{kWh}$, i.e. nearly $10 \%$ of the power generated for industrial usage in the $\mathrm{EU}$ is needed for compressed air supply only [1]. Based on this study, the number of globally installed compressors can be estimated to nearly 860,000 and the related power requirement to nearly 200 billion kWh. Consequently, compressed air plays an important role in the global energy sector and the efficiency of its generation, cleaning, distribution and use needs to be carefully investigated [2].

Compressors are used to compress the incoming atmospheric air to a desired pressure level between a

Corresponding author: Wolfgang Mölter-Siemens, Ph.D., research fields: aerosol physics and filtration. few bar up to more than 400 bar. However, most industrial applications use pressure levels less than 16 bar. Therefore, only this pressure range is considered here. The compressed air inside a compressor is typically dirty, because of the (unwanted but unavoidable) dispersion of lubricating oil droplets and release of solid particles, e.g. from abrasion on top of the intrusion of dust particles with the incoming atmospheric air. On the other side, the cleanliness of the used compressed air has to fulfill different standards depending on the application. The requirements are highest for applications in hospitals, the pharmaceutical or food industry, but even in low-level applications like tire pressurization, the majority of oil droplets and solid particles have to be removed from the compressed air flow.

A variety of filter types are hence used solid particle filters, oil droplet filters, water filters and in special cases even adsorptive filters to remove gaseous pollutants from the air for cleaning the compressed air to the desired level. Filters with different qualities are available to meet the different 
cleanliness requirements. In a typical installation (Fig. 1), compressed air is distributed over the premise using a network of pipes, valves, flanges and sealings. Compressed air filters are on one hand used just downstream of the compressors to protect the network and on the other hand upstream of the consumers and/or processes to protect them. As a rule of thumb, a compressor supplies on average around ten filters.

The compressed air is pushed through these filters which results in a decrease of the downstream pressure level. Typical filters generate a pressure drop of between 50 mbar to 400 mbar depending on the needed quality of the compressed air. Due to this pressure drop across the filters, a certain amount of the stored energy is lost. Consequently, the operational energy usage of a compressed air network can be reduced by using filters with lower pressure drop. The selection and installation of low pressure drop filters, maintaining the desired separation efficiency are not only of high economical interest but can also be very valuable contribution to reaching national, continental and global goals of the reduction of $\mathrm{CO}_{2}$ emissions.

The primary aspect for choosing an appropriate compressed air filter is the minimum requirement for the compressed air quality. The procurement manager may come to a decision based on two thoughts. Firstly, he may choose the filter only based on the purchase price. This results in minimized invested money, but may come at the price of increased operational cost because of the described pressure drop. Secondly, he may take into account the whole life cycle, including the initial investment and the costs (energy) during operation and disposal/recycling. An optimization of the costs and energy usage over the life cycle is a prerequisite for an economically and ecologically sustainable use of compressed air.

However, as of now, there is no support of the end use for the selection of a compressed air filter, based on a realistic assessment of the total cost and energy consumption. Also no study on the performance of compressed air filters was found in the scientific literature. In this study, a first approach towards eco-labeling of compressed air filters is presented based on suitable product category rules [3]. Comparable eco-labeling has already been established for Heating, Ventilation and Air Conditioning (HVAC) filters and electronic household appliances. The approach presented here is closely linked to the labeling of HVAC filters. It is based on $\mathrm{CO}_{2}$ footprint estimations and can be considered as a first step towards labeling of the whole compressed air supply chain [4].

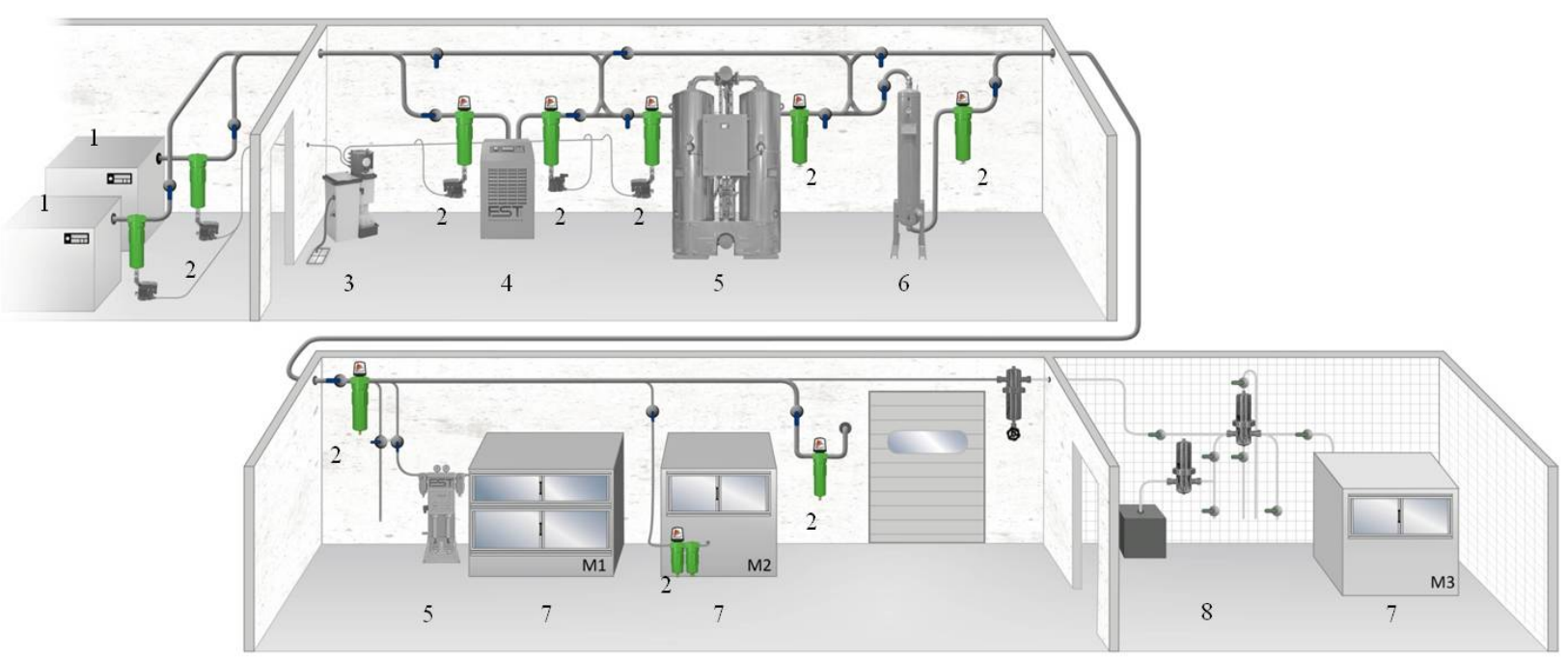

Fig. 1 Scheme of a compressed air supply system consisting of 1-compressors, 2-compressed air filters, 3-water oil separator, 4-refrigeration dryer, 5-adsorption dryer, 6-heat exchanger and 7-process machines (image used with permission). 
Table 1 List of labeling programs in the filtration business.

\begin{tabular}{|c|c|c|c|}
\hline Product category rule & Program & Country & Type \\
\hline Water filter & $\begin{array}{l}\text { EDF-environment and } \\
\text { development foundation }\end{array}$ & Taiwan & $\mathrm{CO}_{2}$ certificate \\
\hline Vehicle air filter & $\begin{array}{l}\text { Environmental declaration of } \\
\text { products }\end{array}$ & Korea & Type III declaration \\
\hline HVAC filter & Eurovent association & Europe & Certificate energy efficiency \\
\hline Vacuum cleaner & $\begin{array}{l}\text { European commission (EU } \\
\text { energy label) }\end{array}$ & Europe & Certificate energy efficiency \\
\hline
\end{tabular}

\section{Development of an Energy Labeling Procedure for Compressed Air Filters}

\subsection{State of Labeling in the Filtration Industry}

The Intergovernmental Panel on Climate Change (IPCC) requests in its Fifth Assessment Report to strengthen and expand energy labeling programs and corresponding public procurement regulations on a regulatory basis [5]. Further on it gives reasons to encourage voluntary agreements on energy targets, adoption of energy management systems or resource efficiency. Additionally, the IPCC requests to raise carbon and/or energy taxes for both buildings and industry, and increase the incentive to introduce energy related labeling. In some fields, like electronic household appliances, such labeling is already very common. In the field filtration, only a few such labeling programs exist. These initiatives are summarized in Table 1. Despite its high importance for the global energy consumption, no such program exists to label compressed air filters. Further information on the success and acceptance of eco-labels and energy labels are given [6-9].

\subsection{Compressed Air Filters Life Cycle, Comparison of Production, Operation and Recycling Phase}

The approach taken here is based on the basic framework of a Life Cycle Assessment (LCA). An LCA is used to assess the environmental impact of a product or process "from cradle to grave", i.e. mainly during three phases, development and production, operation and recycling and waste management [10, 11]. Here, only the $\mathrm{CO}_{2}$ emissions as the probably most important contributor to the filters' environmental impact are taken into consideration. The approach taken here may therefore be understood as a first step towards an LCA for compressed air filters.

The determination of the $\mathrm{CO}_{2}$ emissions during production and disposal/recycling was found to be not straight-forward as the necessary data was not available from the filter manufacturers. In order to estimate the $\mathrm{CO}_{2}$ emission, the typical materials of a filter were listed in first step. These materials are mainly glass fibers, plastics and metal. In second step, the absolute weight of each of the materials was determined. In the third step, the specific $\mathrm{CO}_{2}$ equivalents of those materials were extracted from the ProBas data base (process related basic data for environmental management systems) for both the production phase and the recycling phase. The German Environmental Protection Agency (Umweltbundesamt, UBA) places this service at everyone's disposal [12]. The total $\mathrm{CO}_{2}$ equivalent emissions during the production and recycling phase were calculated based on the data from the database.

The compressed air filter by itself produces no $\mathrm{CO}_{2}$ during operation. $\mathrm{CO}_{2}$ emissions related to the use of compressed air filters, therefore, solely stem from the energy input needed to overcome the pressure drop of the filter. Thus, additional energy has to be provided by the compressor and results in increased electricity usage by the compressor. The (additional) use of electrical power can directly be related to the $\mathrm{CO}_{2}$ emission.

Fig. 2 shows the result of the estimation of $\mathrm{CO}_{2}$ equivalents for a typical $300-\mathrm{m}^{3} / \mathrm{h}$-filter for the production and recycling phase as well as the 


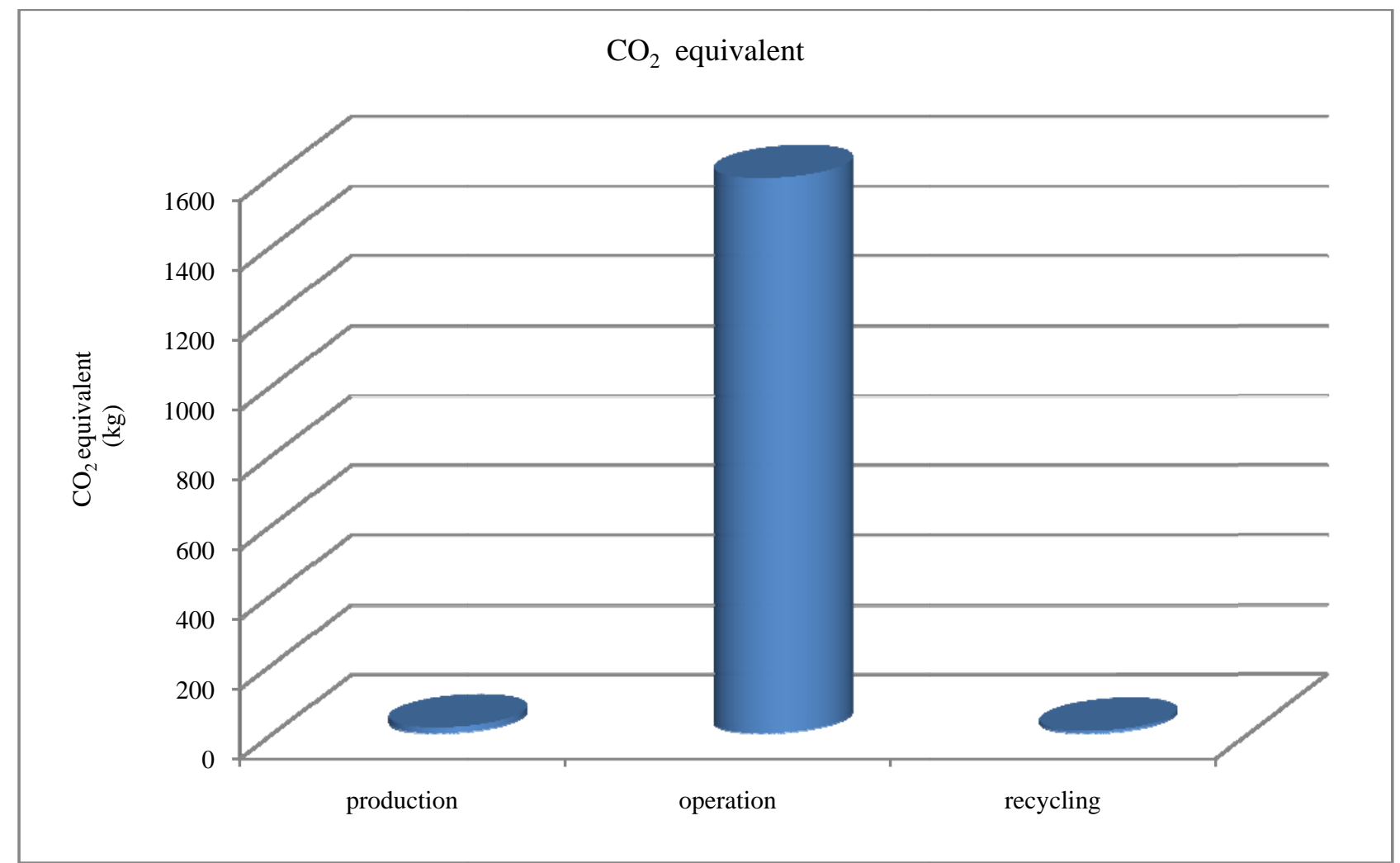

Fig. 2 Assessment of the (equivalent) $\mathrm{CO}_{2}$ emissions of a typical compressed air filter during its life cycle.

operational phase. An operational phase of one year was assumed for the filter based on the very common recommendation of the filter manufacturers for their annual replacement. As can be seen, the $\mathrm{CO}_{2}$ emissions of a compressed air filter are drastically dominated by the operational phase. Such a behavior is confirmed [2]. As mentioned above, the emissions are clearly caused by the energy usage to overcome the pressure drop introduced by the filter. It is therefore obvious that a meaningful eco-labeling must be based on the pressure drop of the compressed air filter, but at the same time, taking into account the filter efficiency. The labeling procedure development is described in the following paragraphs.

\subsection{Product Category Rules}

Compressed air filters are grouped into four categories: coalescence filters, particle filters, adsorptive filters and water separators. The evaluation of compressed air filters is described for these four categories in ISO
12500 (part 1 to part 4). This standard was issued with the intent to facilitate comparisons and qualifications of compressed air filters under defined conditions like manufacturer rated flow rate, pressure level and operating temperature. However, the main focus of this standard is on the separation efficiency. In view of economical and ecological benchmarking of the filters during their operational phase, the pressure drop therefore has to be determined on top of the standardized measurement.

\subsubsection{Coalescence Filters}

Coalescence filters are used to remove oil droplets from a compressed air flow. This is necessary because oil is used for lubrication of many compressors and can be aerosolized during operation. The oil droplets are captured inside the filter, coalesce and saturate the filter. During this process, the pressure drop of the filter rises. The increase of pressure drop among others depends on mass concentration of oil droplets, temperature, sort of oil, flow velocity and some more 
parameters [13-16]. When the saturation reaches a certain level, the oil starts to drain. Under normal conditions, the saturation level and therefore, the pressure drop of the filter remain constant.

For a benchmarking of filters, all these parameters have to be standardized, i.e. constant, equal and the saturation level has to be well defined. Only the pressure drop of the saturated filter, which resembles the filter under normal operation is taken into account for eco-labeling. The measurement procedure is well defined in the ISO 12500-1.

\subsubsection{Particle Filters}

Particle filters are used to remove solid particles from a compressed air flow. Solid particles either stem from the intake air or generated by mechanical processes during compression (e.g. abrasion) or corrosion. The fractional separation efficiency, i.e. the collection efficiency as a function of particle size is measured according to ISO 12500-3. During operation, the collected particles remain in the filter and lead to a continuous increase of the pressure drop. This process of blocking continues during the entire operational phase and is neither reversible nor reaches equilibrium. Thus, the only defined state of pressure drop is provided by the unused filter. Consequently, only the pressure drop of new filters is reproducible and can be taken into account for eco-labeling.

\subsubsection{Adsorptive Filters}

Adsorptive filters are used to remove gaseous contaminations from a compressed air flow. The test procedure is described in ISO 12500-2. The gaseous contaminations are either suspended in the environmental intake air or generated due to vaporization of oil droplets and other components (e.g. additives). The gaseous components are removed mostly by adsorption on activated carbon. The most important parameter is the break through curve which describes the adsorption capacity as function of the loading. The pressure drop is usually not in the main focus when adsorptive filters are tested and used to clean compressed air. The currently available dataset is therefore too scarce for the development of a meaningful eco-labeling and therefore, not further pursued here.

\subsubsection{Water Separators}

Water separators are used to remove water droplets or even huge amounts of liquid water from compressed air flows. The test procedure is described in ISO 12500-4. Compared to coalescence, particle and adsorptive filters water separators are not widely used. Thus, the currently available dataset is too scarce for the development of a meaningful eco-labeling and therefore, is not further pursued in this work.

In the next paragraphs, the development of labeling procedures concerning the operation behavior of compressed air filters is described. The evaluation is limited to coalescence and particle filters for rated pressure levels less than 16 bar, because of their high relevance for industry and the availability of a sufficient dataset.

\section{Methods and Results}

\subsection{General}

Compressed air filters are available in a huge variety of configurations and models. They can totally differ in flow rate, size, pressure level, separation efficiency and pressure drop. For example, the offered flow rates of compressed air filters are found in a range between less than $35 \mathrm{~m}^{3} / \mathrm{h}$ up to more than $10,000 \mathrm{~m}^{3} / \mathrm{h}$. In addition, different classes of separation efficiencies are available in each of more than 20 filter sizes.

The filter size is defined by its rated flow rate. The filters of different size within the same filter series are commonly designed to exhibit the same pressure drop if the filters are used with their rated flow rate. Fig. 3 shows three of compressed air filters with very different sizes. Taking into account the different categories of compressed air filters, a common labeling procedure is only possible with a clear and simple structural classification of all the filters. 


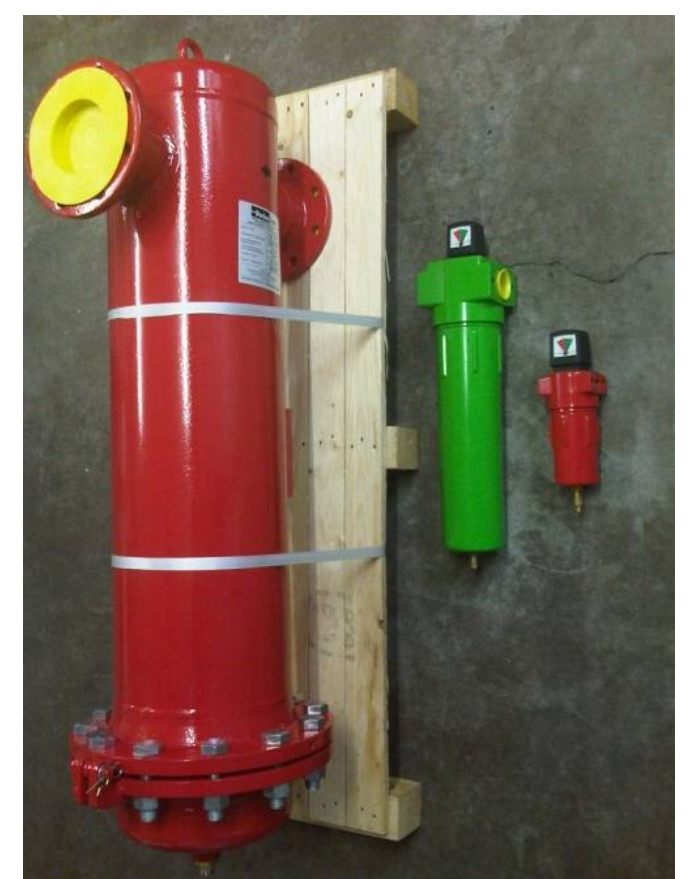

Fig. 3 Three compressed air filters of different sizes (flow rates approximately between $50 \mathrm{~m}^{3} / \mathrm{h}$ and $5,000 \mathrm{~m}^{3} / \mathrm{h}$ ).

An eco-labeling method has to be based on a comparison of the pressure drop of filters during operation. Due to the different operation, application and internal geometries, separate labels have to be used for the different product category rules, i.e. for coalescence and particle filters. It is furthermore certainly not very meaningful to compare the pressuredrop of a low efficiency filter (separation efficiency of about 85\%) to those of a high efficiency filter (separation efficiency of about 99.99\%).

Taking into account the aforementioned thoughts, a two-level classification was developed for compressed air filters. The first level of classification is the product category (coalescence filters and particle filters). The second level of classification is the separation efficiency. This second classification level is necessary, because a higher pressure drop may be permissible for filters with a higher separation efficiency. By measuring both the separation efficiency and the pressure drop, a filter can first be classified according to its separation efficiency. Afterwards, the pressure drop is evaluated to judge on the energy efficiency or carbon footprint of this filter within its separation efficiency class.

To take into account the different sizes of compressed air filters, the tests of separation efficiency and pressure drop always have to be carried out at the rated flow rate of the filters. The rated flow is an operational parameter which is defined by the manufacturer and clearly assigned in the filter spec sheet. The specification of the rated flow belongs to the responsibility of the manufacturer.

Last not least, a test procedure has to be applied a well defined protocol in order to assure good reproducibility irrespective of the filter test laboratory. This ensures defined and equal test conditions, concerning challenge aerosol mass concentration, pressure level, droplet or particle size distribution, sort of oil or particles, temperature and humidity for each of the tested compressed air filters. In the case of compressed air filters, the ISO 12500 part 1 (coalescence filters) and part 3 (particle filters) were taken as the basis for the measuring method to establish an ec-labeling for compressed air filters.

During the last decade, IUTA tested a multitude of compressed air filters applying ISO 12500 procedures. A database was generated from the test results. The results were statistically evaluated and anonymously grouped in appropriate classes of separation efficiencies with respect to the category rules as described below. All filter manufacturers provided their written consent to use their anonymized data here.

\subsection{Coalescence Filters}

The classification of the separation efficiencies of coalescence filters is based on the purity classes of compressed air filters. These purity classes are well defined in ISO 8573 part 1 and are based on the measured oil content in the compressed air. Four classes with different maximum concentrations of 5 $\mathrm{mg} / \mathrm{m}^{3}, 1 \mathrm{mg} / \mathrm{m}^{3}, 0.1 \mathrm{mg} / \mathrm{m}^{3}$ and $0.01 \mathrm{mg} / \mathrm{m}^{3}$, respectively are given in the standard. On the other hand, the test procedure for benchmarking compressed 
Table 2 Proposed separation efficiency classes of coalescence filters.

\begin{tabular}{ll}
\hline Class no. & Range of separation efficiencies (\%) \\
\hline 1 & $>99.9$ \\
2 & $99-99.9$ \\
3 & $90-99$ \\
4 & $<90$ \\
\hline
\end{tabular}

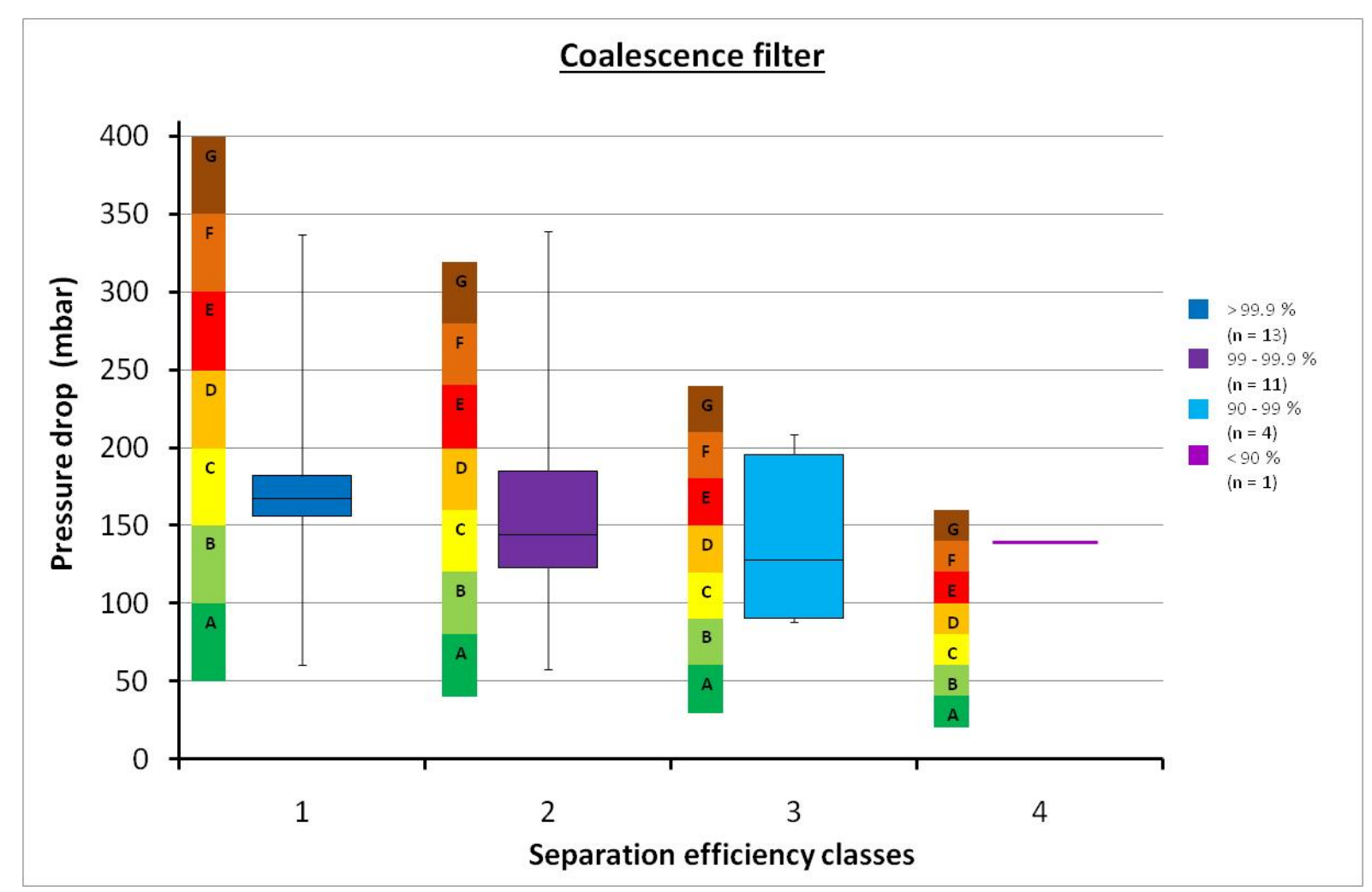

Fig. 4 Pressure drop ranges of coalescence filters for the four different separation efficiency classes according to Table 2 along with a proposal for energy labeling within each class no. denotes the number of filters found in each class.

air filters is defined in ISO 12500 part 1 . Within this standard, the common challenge concentration of the oil aerosol is specified to $10 \mathrm{mg} / \mathrm{m}^{3}$. Based on these two standards, four separation efficiency classes are defined in this work and listed in the Table 2. A total of 29 coalescence filters were evaluated, out of which 13 fell into class 1,11 into class 2, four into class 3 and only one into class 4 . Hence, the majority of investigated filters had a high separation efficiency of $>99 \%$.

Fig. 4 shows the result of the evaluation of IUTA database concerning the above mentioned separation efficiency classes and the measured accompanying pressure drop. The pressure drop is shown for each size class as a box plot diagram. The first, second (median) and third quartile are represented as the box, whereas, the whiskers give the minimum and maximum measured pressure drop. The box plot diagram shows the expected correlation of the mean pressure drop and the separation efficiencies within classes 1-3, i.e. a higher separation efficiency causes a higher pressure drop. Only the pressure drop of the filter in class 4 did not follow this rule. It should be noted that class four currently only contains a single filter which may not be representative. Class 4 filters are typically used as pre-filters and have a different internal geometry than higher class filter, which may be the reason for the rather high pressure drop. 
However, production costs for such pre-filters are usually lower than for higher class filters.

On the left hand side of each class (Fig. 4), the suggested pressure drop ranges for the eco-labeling are plotted. The background for suggestion is:

The pressure drop labeling depends on the separation efficiency classes (label A in class 1 allows a higher pressure drop than label A in class 4);

The pressure drop range in each label gets smaller with lower separation efficiency;

The whole range in each separation efficiency class should cover most of the measured pressure drop values;

The pressure drop range is subdivided into seven equidistant labels $A$ through $G$ (comparable to the labeling for household appliances).

This suggestion is similar to the suggestion in the Eurovent Classification of HVAC Filters.

Fig. 4 clearly shows that the distribution of pressure drop within each class is rather scattered. The reason for the scatter is not yet clear, but likely caused by different filter geometries and materials. Since some of the measurements are already older, the filters are no longer available for inspection. Future investigations will try to scrutinize this effect more.

\subsection{Particle Filters}

The classification of the separation efficiencies of particle filters is based on the classification of HEPA/ULPA filters (High Efficiency Particulate Air filter, Ultra Low Penetration Air filter) which is defined in DIN EN 1822 (German European regulation). In this study, these classes are combined to get at least 5 classes of separation efficiencies for compressed air filters as shown in Table 3.

The DIN EN 1822 specifies the particle size at which the separation efficiencies have to be determined to the Most Penetration Particle Size (MPPS). The MPPS depends among others on the face velocity and the structural parameters of the filter medium and is typically found in the range of about
$0.1 \mu \mathrm{m}$. This particle size can be measured easily at ambient conditions but at a pressure of e.g. 10 bar, particles smaller than approximate $0.2 \mu \mathrm{m}$ are not detectable due to the lack of suitable measurement equipment. For the detection of particles in the size of $0.1 \mu \mathrm{m}$, the compressed air has to be expanded to atmospheric pressure to use conventional aerosol measurement technology. But due to the reasons listed below, it is suggested to measure under pressure and at a particle size $>0.2 \mu \mathrm{m}$.

A particle size larger than $0.2 \mu \mathrm{m}$ is readily measurable under compressed conditions (e.g. using welas P or HP, Palas GmbH, Karlsruhe, Germany).

Expansion of compressed air to ambient conditions is generally possible by using a diffusor. The size distribution of the expanded aerosol can then be measured down to particle sizes of $2.5 \mathrm{~nm}$ using a Scanning Mobility Particle Sizer (SMPS, available from a variety of manufacturers). However, the expansion is known to alter the size distribution due to shear forces acting on the particles/droplets and evaporation of the droplets and therefore, introduces rather strong artifacts. Since the particle transfer function of the diffusors is unknown, these artifacts cannot be corrected. The measurement of particle size distributions under pressure is thus more reliable.

In ISO 12500 part 1, the aerosol for the testing compressed air filter is described. The number size distribution of the polydisperse test aerosol should have a maximum between $0.1 \mu \mathrm{m}$ and $0.4 \mu \mathrm{m}$. With the commonly used test aerosol generators, the produced size distributions are fairly broad and thus, there are still sufficient particles in the size larger than $0.2 \mu \mathrm{m}$ to measure the separation efficiency with high statistical confidence even of high efficient filters.

The Eurovent Association offers more than ten certification programs. One of these programs applies to air filter elements rated and sold as "Medium and Fine Filters Class M5, M6, F7-F9" as defined in EN 779:2012. EN 779 defines the test procedure to validate those filters and the definition of the different 
Table 3 Separation efficiency classes of HEPA and ULPA filters according to DIN EN 1822 and suggested classes for compressed air particle filters.

\begin{tabular}{|c|c|c|c|}
\hline \multicolumn{2}{|c|}{ DIN EN 1822 high efficiency air filters } & \multicolumn{2}{|c|}{ This work compressed air filters } \\
\hline Class & Separation efficiency (\%) & Class & Separation efficiency (\%) \\
\hline U17 & > 99.999995 & 1 & > 99.99995 \\
\hline U16 & 99.99995-99.999995 & 2 & 99.995-99.99995 \\
\hline $\mathrm{U} 15$ & 99.9995-99.99995 & 3 & 99.5-99.995 \\
\hline H14 & 99.995-99.9995 & 4 & 85-99.5 \\
\hline H13 & 99.95-99.995 & 5 & $<85$ \\
\hline E12 & 99.5-99.95 & & \\
\hline E11 & $95-99.5$ & & \\
\hline E10 & 85-95 & & \\
\hline
\end{tabular}

separation efficiency classes is based on the separation efficiency belonging at a particles size of $0.4 \mu \mathrm{m}$, which is assumed to be close to the MPPS of these filters and can be readily measured by filter test institutes using optical aerosol spectrometers. Thus, the procedure to define separation efficiency classes by regarding just one particle size is well established and accepted by the industry.

Taking the arguments into account, the available data on size dependent particle separation efficiencies of compressed air filters were checked in order to define a particle size that can be used to define the separation efficiency classes. The IUTA database includes a total of 23 particle filters which were evaluated.

The structure of the graphical representation of the results is the same as seen in the Fig. 4. The primary step is the classification of the separation efficiency and the secondary step according to the accompanied pressure drop within each class. The separation efficiency was evaluated for five different particles sizes $(0.21 \mu \mathrm{m}, 0.29 \mu \mathrm{m}, 0.44 \mu \mathrm{m}, 0.65 \mu \mathrm{m}$ and 0.94 $\mu \mathrm{m})$. The evaluated sizes were defined by the pressure-proof optical spectrometer (Palas welas system) used for the measurements. The evaluation for the $0.21 \mu \mathrm{m}$ and $0.29 \mu \mathrm{m}$ particles showed nearly the same results concerning the number of filters per efficiency class, resulting in very similar box plots for the accompanying pressure drop. The results for the other sizes were found to not be very meaningful. Regarding the $0.44 \mu \mathrm{m}$ particles for example, nearly all the filters were found in the same separation efficiency class (class 2) because larger particle are separated with increasing efficiency. Thus, the difference in separation efficiency becomes smaller and smaller. This also shows that for the investigated filters, the MPPS was below $0.44 \mu \mathrm{m}$. Therefore, only the results for the smaller particles can be used for the classification of the filters for separation efficiencies > $85 \%$. On the other hand, the $0.21 \mu \mathrm{m}$ particles size is very close to the lower detection limit of the available particle measuring systems for compressed air (typically around $0.2 \mu \mathrm{m}$ ). It is hence suggested to measure the separation efficiency for particles with a size of approximately $0.3 \mu \mathrm{m}$ (here $0.29 \mu \mathrm{m}$ ) for the classification of the separation efficiency of particle filters.

Fig. 5 shows the result of the evaluation of the IUTA database for particle filters concerning the above mentioned separation efficiency classes and the accompanied measurement of the pressure drop. According to the classes defined in Table 3, only a single filter from the IUTA database was found to comply with the requirements for class 1 , six filters fall into class 2, nine filters into class 3 and four filters each into classes 4 and 5.

The box plot diagram shows the expected correlation of the mean pressure drop and the separation efficiencies within classes $1-4$, i.e. the higher the separation efficiency the higher the pressure drop. That's what could be expected. However, the pressure drop of the class 5 filters deviate from that correlation and show 


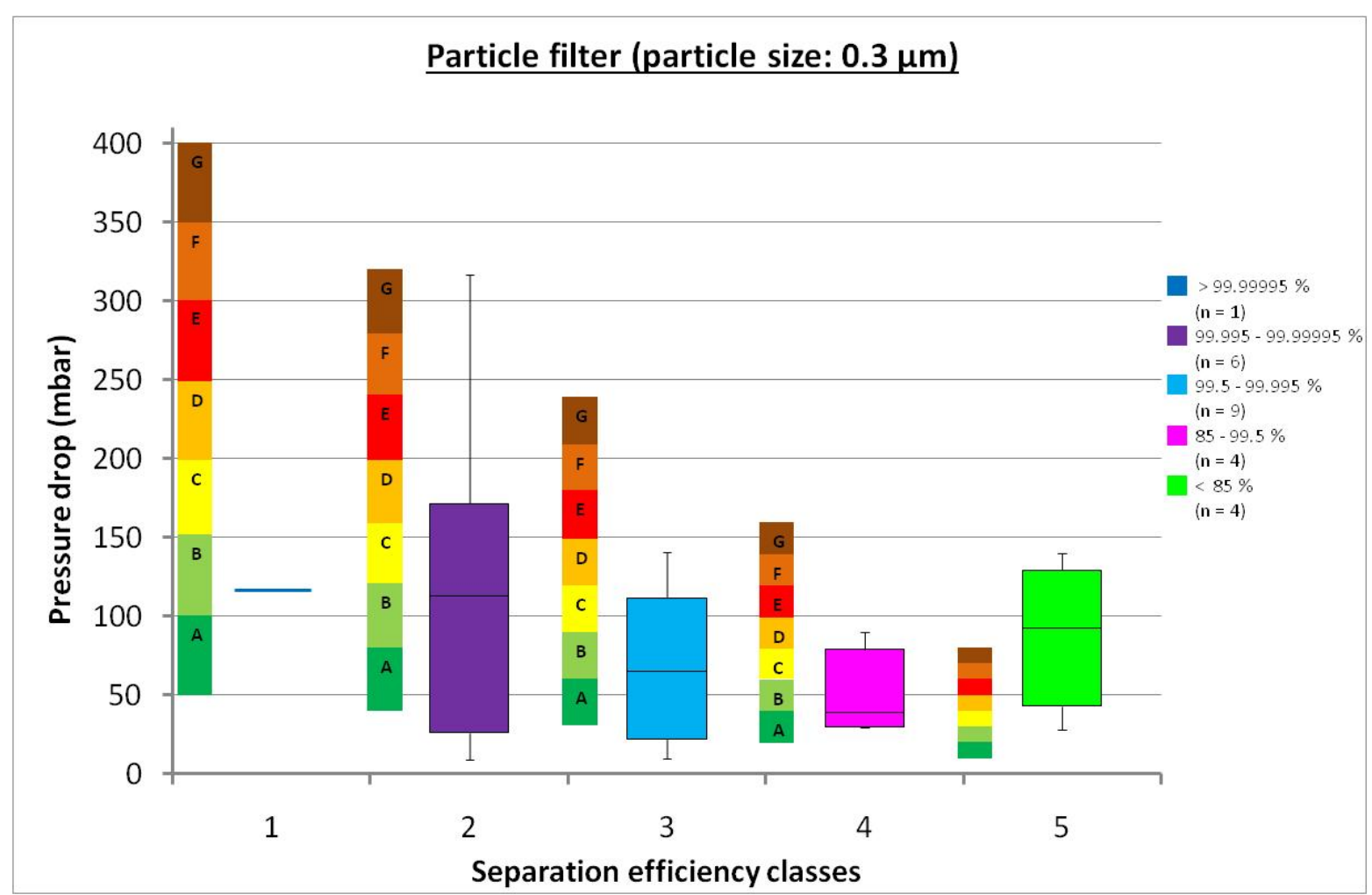

Fig. 5 Ranges of pressure drop for particle filters of different efficiency classes according to Table 3 along with a proposal for energy labeling within each class; separation efficiency measured for a particle size of $0.3 \mu \mathrm{m}$, no. denotes the number of filters found in each class, left to each box plot, the suggested pressure drop ranges for the eco-labeling are given, based on the same arguments as for the coalescence filters.

higher pressure drop. This is comparable to the findings with coalescence filters, where also the filters with the lowest efficiency showed a higher pressure drop than expected from the correlation within the higher classes. Class 5 filters are also used as pre-filters and have a different geometry than filters in classes 1-4, which is assumed to produce the higherthan expected pressure drop. As can be seen in Fig. 5, the pressure drop data for all classes with more than a single filter are quite scattered.

\section{Conclusion}

In this study, an approach towards energy labeling of compressed air filters based on carbon footprint was introduced. This follows a recommendation by the Intergovernmental Panel on Climate Change [6] who recommended the introduction of energy labeling in a wide range of applications as a tool to reduce the $\mathrm{CO}_{2}$ footprint in industrial processes. The approach presented in this work is mainly based on the operational behavior of these filters, because it was shown that the $\mathrm{CO}_{2}$ footprint of the production, distribution and recycling phase can nearly be neglected compared to $\mathrm{CO}_{2}$ footprint of the operational phase. On the other hand, the $\mathrm{CO}_{2}$ footprint of the operational phase itself is dominated by the pressure drop of those filters during operation. The filters themselves do not produce any $\mathrm{CO}_{2}$ but the higher the pressure drop of the installed filters the higher the electrical power consumption of the compressors. The pressure drop is unavoidable and the main goal to reduce the $\mathrm{CO}_{2}$ emission is among others the installation of compressed air filters having lowest pressure drop at required separation efficiency. A procedure was developed to compare the energetic footprint of compressed air filters even in the case of totally different applications, wide range of separation efficiency classes and widely spread operational 
parameters. In a first step, the compressed air filters were divided in categories of application. In the present case, the range of applications was limited to coalescence and particle filters for compressed air, because a sufficient database was only available for these two filter types. A similar labeling procedure can also be applied to adsorption filters or water separators for compressed air in the future, when sufficient data are available. In a second step, the range of separation efficiencies of filters belonging to a specified category were divided in several classes and defined according to some useful current normative regulations. Last but not least, the pressure drop of the filters of a specified category and a certain separation efficiency class determines the basis for an energy label of a compressed air filter. The evaluation of a total of 29 coalescence and 23 particle filters revealed a large scatter of the pressure drop of the filters within each efficiency class. This results in a similarly large scatter of the operational energy requirements and hence costs during the use phase of these filters. Although the number of filters evaluated in this study is still rather small, this already clearly shows the need for an energy labeling system in order to allow the end user to choose a filter which keeps the costs and $\mathrm{CO}_{2}$ emissions low. Still, the approach presented here should be seen as a first proposal towards energy labeling of compressed air filters that will need to be refined as more data become available. The introduction of a quality factor or figure of merit as an additional parameter may also be useful in the future $[17,18]$.

\section{Acknowledgement}

The IGF project $17992 \mathrm{~N}$ has received funding via AiF within the Industrial Collective Research Program (IGF) from the German Federal Ministry of Economics and Energy, based on a decision of the German Bundestag. The support is gratefully acknowledged.

\section{References}

[1] Radgen, P., and Blaustein, E. 2001. Compressed Air
Systems in the European Union, Energy, Emissions, Savings Potential and Policy Actions. Stuttgart, Germany: LOG_X Publishing.

[2] Zanghelini, G. M., Cherubini, E., Orsi, P., and Soares, S. R. 2014. "Waste Management Life Cycle Assessment: The Case of a Reciprocating Air Compressor in Brazil.” Journal of Cleaner Production 70: 164-174.

[3] Minkov, N., Schneider, L., Lehmann, A., and Finkbeiner, M. 2015. "Type III Environmental Declaration Programmes and Harmonization of Product Category Rules: Status Quo and Practical Challenges.” Journal of Cleaner Production 94: 235-246.

[4] Clift, R. 1993. "Life Cycle Assessment and Eco-labeling." Journal of Cleaner Production 1 (3-4): 155-159.

[5] Intergovernmental Panel on Climate Change (IPCC). 2015. “Synthesis Report for Policymakers.” Accessed November 11, 2015. https://www.ipcc.ch/pdf/assessment-report/ar5/syr/SYR_ AR5_FINAL_full.pdf.

[6] Delmas Magali, A., and Grant Laura, E. 2014. "Eco-labeling Strategies and Price-Premium: The Wine Industry Puzzle.” Business \& Society 53 (1): 6-44.

[7] Heinzle, S. L., and Wüstenhagen, R. 2011. "Dynamic Adjustment of Ecolabeling Schemes and Consumer Choice the Revision of the EU Energy Label as a Missed Opportunity?” In Business Strategy and the Environment, 60-70.

[8] Larson Bruce, A. 2003. "Eco-labels for Credence Attributes: The Case of Shade-Grown Coffee.” Envir. Dev. Econ. 8 (3): 529-547.

[9] Sammer, K., and Wüstenhagen, R. 2006. "The Influence of Eco-labelling on Consumer Behaviour." Discrete Choice Analysis 3: 185-199.

[10] Baumann, H., and Tilman, A. M. 2004. The Hitch Hiker's Guide to LCA, an Orientation in Life Cycle Assessment Methodology and Application. Lund, Sweden: Student litteratur Ab; Auflage: 1.

[11] Bratt, C., Hallstedt, S., Robèrt, K. H., Broman, G., and Oldmark, J. 2011. "Assessment of Eco-labelling Criteria Development from a Strategic Sustainability Perspective.” Journal of Cleaner Production 19 (14): 1631-1638.

[12] Umweltbundesamt (UBA). 2015. "Prozess Orientierte Basis Daten Für Umwelt-management Systeme-ProBas.” Accessed November 11, 2015. http://www.probas.umweltbundes-amt.de/php/index.php.

[13] Kampa, D. 2009. "A Model for Steady-State Oil Transport and Saturation in a Mist Filter." In Elektronisches Voll-textarchiv-Scientific Articles Repository (EVA-STAR), 1720-1724.

[14] Mölter-Siemens, W. 2011. "Separation of Ultrafine Droplets with Multi-Layer Fibroid Filter Media Using the Example of Compressed Air Filtration.” Filtration \& 
Separation 12: 56-60.

[15] Mölter-Siemens, W. 2012. "Filtration Properties of Compressed Air Filters at Rated Flows between $50 \mathrm{Nm}^{3} / \mathrm{h}$ and 3,000 $\mathrm{Nm}^{3} / \mathrm{h} . "$ In Proceedings World Filtration Congress, 55.

[16] Raynor, P. C. 2000. "The Influence of Accumulated Liquid on Fibrous Filter Performance.” J. Aerosol Sci. 31:
19-34.

[17] Brown, R. C. 1993. Air Filtration. London: Pergamon Press.

[18] Wang, J., Kim, S. C., and Pui, D. Y. H. 2008. "Figure of Merit of Composite Filters with Micrometer and Nanometer Fibers.” Aerosol Science and Technology 42: 722-728. 